Check for updates

Cite this: RSC Adv., 2019, 9, 35077

\title{
Surface modification of ZnMgAl-coated steel by dielectric-barrier discharge plasma $\uparrow$
}

\author{
Steffen Knust, (D) Andreas Kuhlmann, Teresa de los Arcos (iD) and Guido Grundmeier* \\ In this study, ZnMgAl alloy coated steel sheets were exposed to a dielectric-barrier discharge plasma with \\ different gas mixtures ( $\mathrm{Ar}, \mathrm{Ar}+5 \% \mathrm{O}_{2}, \mathrm{Ar}+5 \% \mathrm{H}_{2} \mathrm{O}$ ). Five different plasma-induced processes were \\ identified at the surface: (i) etching of aliphatic carbon groups, (ii) conversion of absorbed carboxylates \\ to carbonates, (iii) field-induced migration of $\mathrm{Zn}$ and $\mathrm{Mg}$ towards the surface, (iv) increased oxide layer \\ thickness, and ( $v$ ) homogenization of the surface potential of the originally very heterogeneous alloy. The \\ relative contribution of each process depended on the specific gas mixture. Peel-test studies showed \\ that all atmospheric-pressure plasma treatments improved the adhesive properties of the alloy coating \\ for two different adhesives (acrylate and epoxy amine). The highest improvement was associated to the \\ case of $\mathrm{Ar}+5 \% \mathrm{H}_{2} \mathrm{O}$ gas mixture, where all described surface processes took place to a high degree.
}

Received 13th September 2019 Accepted 21st October 2019

DOI: $10.1039 / c 9 r a 07378 g$

rsc.li/rsc-advances plasma treatments removed carbon contaminations from the surface and change the top oxide layer thickness. The plasma treatments were also seen to improve the ordering and stability of phosphonic acid self-assembled monolayers for further functionalisation of the surface. Giza et al. showed that a reducing low-pressure plasma treatment of $\mathrm{ZnMg}_{2}$ surfaces affected the band gap as well when using a mixture of $\mathrm{Ar} / \mathrm{H}_{2}$ as the working gas. ${ }^{9}$ The reducing plasma led to the formation of a polymer/oxide/metal interface highly stable against corrosion.

Even though low-pressure plasma treatments seem to be beneficial, the vacuum-based technology needs makes these treatments cost-intensive and limited in the number of pieces that can be treated simultaneously. Atmospheric-pressure plasma treatments, on the other hand, have the potential to be applied in in-line processes as cost efficient and nonpolluting technology. In this context, dielectric-barrier discharges (DBD) have shown the advantage of treating large areas homogeneously. However, it is not fully clear how Znbased alloy coatings respond to such DBD-treatments.

The aim of this work is to investigate the effect of DBDplasma treatments on $\mathrm{ZnMgAl}$-alloys. One of the goals is to determine the nature of the surface modifications to the $\mathrm{ZnMgAl}$-alloy as a function of the plasma gas composition (pure $\mathrm{Ar}, \mathrm{Ar} / \mathrm{O}_{2}$ and $\mathrm{Ar} / \mathrm{H}_{2} \mathrm{O}$ ). The other is to evaluate the influence of the plasma-induced changes on the adhesion of two different adhesives (epoxy-based and acrylate-based).

\section{Experimental part}

\subsection{Materials}

All solvents were analytical reagent grade and were used without further purification. ZnMgAl alloy coated mild steel sheets with a sheet thickness of $1 \mathrm{~mm}$ and a coating thickness of about 5
Straße 100, 33098 Paderborn, Germany. E-mail: guido.grundmeier@uni-paderborn.de

$\dagger$ Electronic supplementary information (ESI) available. See DOI: 10.1039/c9ra07378g 
$\mu \mathrm{m}$ were supplied by ThyssenKrupp Steel. The alloy had a composition in the melt of $98 \mathrm{wt} \% \mathrm{Zn}, 1 \mathrm{wt} \% \mathrm{Al}$ and $1 \mathrm{wt} \% \mathrm{Mg}$. All samples were cleaned consecutively in THF, isopropanol and ethanol, each $10 \mathrm{~min}$ in an ultrasonic bath.

\subsection{Plasma treatment}

The plasma treatment was carried out in a homemade plasma chamber, whose schematic is shown in Fig. 1a (additional information can be found in ref. 9). The advantage of such setup is that the sample can be moved between the plasma treatment position and an analytic position without opening the chamber to air. At the analytic position, discrete polarisation modulated IRRAS (DPM-IRRAS) and Kelvin probe (KP) measurements were performed before and after the plasma treatments.

The DBD plasma electrode consisted of an $18 \mathrm{~mm}$ diameter copper disk. The metal disk was capped with a $20 \mathrm{~mm}$ diameter $\mathrm{Al}_{2} \mathrm{O}_{3}$ ceramic disk of $2 \mathrm{~cm}$ thickness, which acted as dielectric barrier. The whole electrode was enclosed in a polyether ether ketone (PEEK) container. The sample was grounded and acted as counter electrode. The distance between the sample and the electrode was adjusted to around $1 \mathrm{~mm}$ and was kept constant during the experiment.

The gases used had a purity of $99.999 \%$ and were purchased from Linde. Three different gas mixtures were compared in this

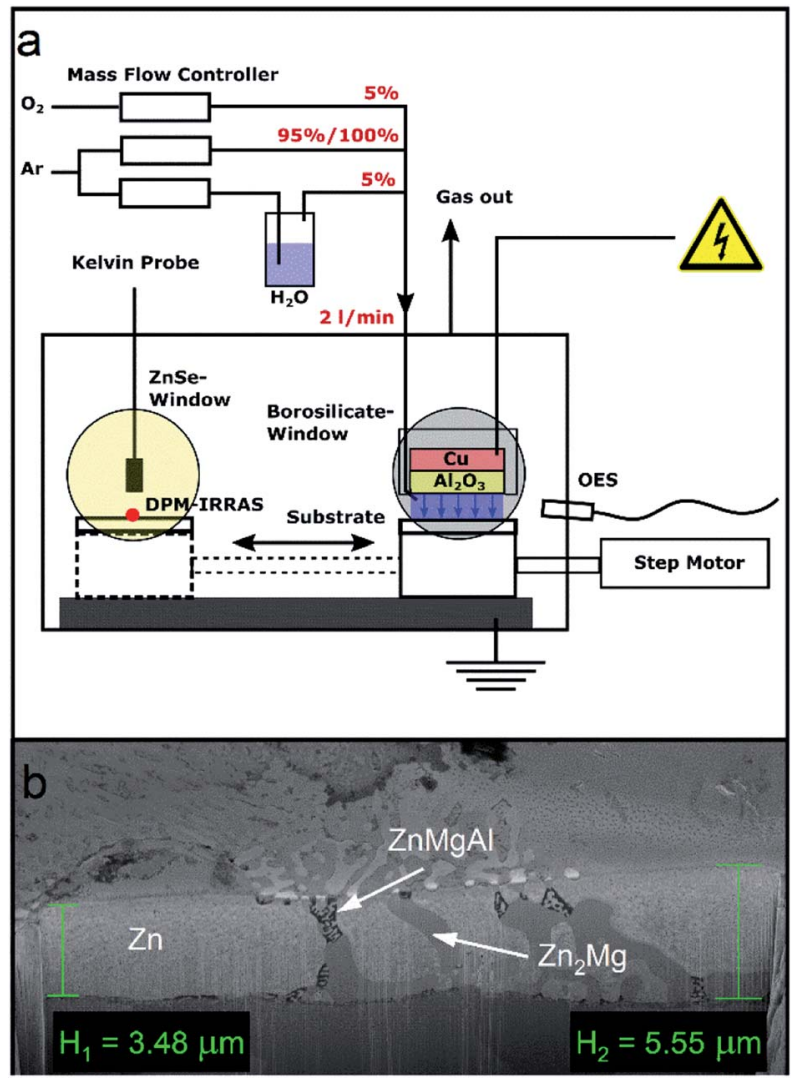

Fig. 1 (a) DBD plasma experimental setup used to treat the ZnMgAl surface and to investigate the plasma induced changes in situ with discrete polarized modulated FT-IRRAS and Kelvin probe. (b) SEM cross-section of the native $\mathrm{ZnMgAl}$ alloy layer onto steel. work. Pure argon, argon with 5\% oxygen $\left(\mathrm{Ar} / \mathrm{O}_{2}\right)$ and argon with $5 \%$ water $\left(\mathrm{Ar} / \mathrm{H}_{2} \mathrm{O}\right)$. The flows were controlled using mass flow controller (red-y-compact, Vögtlin instruments, Swiss) calibrated to the respective gases. To determine the flow ratio, the oxygen content was measured before the experiments with a lambda probe (BA 4510, Bühler, Germany) and the water content with a humidity sensor (UTF75, Sensor-Tec, Germany). The gas flow ratios were adjusted so that the total flow was always $21 \mathrm{~min}^{-1}$. All measurements were performed at atmospheric pressure.

A G2000 high voltage generator (Redline, Germany) was used to power the discharge. The voltage was monitored using a high voltage probe (PHV 4002-3, PMK, Germany) and an oscilloscope (HMO 1002, Rohde \& Schwarz, Germany). The discharge frequency was $35 \mathrm{kHz}$, leading to a sinus-like voltage signal. Prior to the measurement the ignition voltage for the given electrode-sample distance was determined for each gas mixture. For each gas mixture, the voltage was set $165 \mathrm{~V}$ higher than the ignition voltage thus leading to a discharge applied voltage of $2.9 \mathrm{kV}$ for pure $\mathrm{Ar}, 3.6 \mathrm{kV}$ for $\mathrm{Ar} / \mathrm{O}_{2}$ and $2.6 \mathrm{kV}$ for $\mathrm{Ar} / \mathrm{H}_{2} \mathrm{O}$.

Before each plasma treatment, KP and DPM-IRRAS reference measurements were recorded for each sample. During the reference measurements, the chamber was flushed with pure argon $\left(21 \mathrm{~min}^{-1}\right)$ during 15 minutes. When a gas mixture was used, the second gas was added continuously $5 \mathrm{~min}$ before the plasma was ignited. When adding the reactive gas, the flow of pure argon was correspondingly reduced, so that a total gas flow of $21 \mathrm{~min}^{-1}$ was maintained.

The duration of the plasma treatment in all cases was $60 \mathrm{~s}$, after which the samples were directly moved to the analytic position and DPM-IRRAS and KP were measured at the same spot where the respective reference measurement was recorded. During the measurements, the chamber was continuously flushed with pure Ar.

2.2.1 In situ optical emission spectroscopy. The plasma discharge was monitored by optical emission spectroscopy (OES) to investigate the plasma composition and reproducibility. The spectrometer was a USB2G (Plasus GmbH, Germany) with a resolution of $0.4 \mathrm{~nm}$. The light passed through a glass window (cut-off at about $290 \mathrm{~nm}$ ), was collected by a quartz lens and transmitted to the spectrometer by a glass fibre. The distance to the discharge was approximately $60 \mathrm{~mm}$.

2.2.2 In situ discrete polarization modulated IRRAS studies. The plasma-treated surfaces were characterized in situ by means of discrete polarization modulated IRRAS (DPMIRRAS). ${ }^{13}$

The spectrometer used was a Bruker Vertex 70 (Bruker Optik $\mathrm{GmbH}$, Germany). The IR-beam was focused on the sample with a gold-coated parabolic mirror through a ZnSe window. The beam reflected from the sample exited the chamber through a second $\mathrm{ZnSe}$ window and was guided with gold-coated mirrors through a rotatable KRS-5 polariser. The polariser was moved between two settings, one horizontal (p-polarized) and one perpendicular to the plane of incidence (s-polarized). The beam was then focused on a liquid-nitrogen cooled mercurycadmium-telluride detector (MCT). The sample was investigated under an incidence angle of $75^{\circ}$. The final absorbance 
spectrum (A) was calculated by subtracting the averaged absorbance spectrum of s-polarized infrared light $\left(A_{\mathrm{s}}\right)$ from the averaged absorbance spectrum of p-polarized infrared light $\left(A_{\mathrm{P}}\right)$ according to the following equations:

$$
\begin{gathered}
A_{\mathrm{p}}=-\log \left(\frac{I_{1 \mathrm{p}}}{I_{0 \mathrm{p}}}\right) \\
A_{\mathrm{s}}=-\log \left(\frac{I_{1 \mathrm{~s}}}{I_{0 \mathrm{~s}}}\right) \\
A=A_{\mathrm{p}}-A_{\mathrm{s}}
\end{gathered}
$$

$I_{1 \mathrm{p}}$ and $I_{0 \mathrm{p}}$ are the intensities after and before plasma treatment for the p-polarized light, while $I_{1 \mathrm{~s}}$ and $I_{0 \mathrm{~s}}$ are the intensities after and before plasma treatment for the s-polarized light. The $I_{0}$ and $I_{1}$ measurements were performed at the same spot for each sample. Four spectra of 64 scans each were averaged per polarisation direction, with s- and p-polarized light measurements performed alternatively. The spectral resolution was $4 \mathrm{~cm}^{-1}$.

2.2.3 In situ Kelvin probe studies. The plasma-induced changes in the chemistry and semi-conduction properties of the sample were measured in situ using a Kelvin probe (KP). The tip was made of $\mathrm{CrNi}$ and had a diameter of $2 \mathrm{~mm}$. Potentials were measured as a function of bias voltages at three different distances from the surface, following the measurement principle used by Tahara et al. ${ }^{\mathbf{1 4}}$ At each distance, the potential was recorded at 40 different bias voltages. Since the measured peakto-peak distance depends linearly on the bias and is quadratically proportional to the tip-sample distance, ${ }^{15}$ the three measurements produced three linear plots with different slopes dependent on the tip-sample distance. The potential at the intersection of the linear plots gives the surface potential. With this method, the error in the determination of the surface potential was between $10-80 \mathrm{mV}$.

\subsection{Ex situ polarization modulated IRRAS}

Polarization modulated IRRAS (PM-IRRAS) was performed to study the surface chemistry before the plasma treatment. ${ }^{16} \mathrm{~A}$ ZnSe photo-elastic modulator (PMA50, Bruker Optik GmbH, Germany) modulates an aluminium wire grid at $50 \mathrm{kHz}$ to polarize the light, which is attached to a Vertex V70 spectrometer (Bruker Optik GmbH, Germany). The sample was investigated under an incident angle of $80^{\circ}$. The reflected light was collected using a ZnSe lens onto a liquid-nitrogen cooled MCT detector. 512 single scans were measured with a resolution of $4 \mathrm{~cm}^{-1}$.

\subsection{Scanning Kelvin probe force microscopy}

Potential scanning Kelvin probe force microscopy (SKPFM) was performed using a MFP-3D-AFM setup (Asylum Research, England). A platinum-coated tip with a force constant of $40 \mathrm{~N}$ $\mathrm{m}^{-1}$ and a resonance frequency of $350 \mathrm{kHz}$ was used. The scan rate was $0.1 \mathrm{~Hz}$ and the resulting images were $70 \times 70 \mu \mathrm{m}^{2}$ in size.

\subsection{Field emission scanning electron microscopy and energy-dispersive X-ray spectroscopy}

Field emission scanning electron microscopy (FE-SEM) and energy-dispersive X-ray (EDX) analysis were performed by means of a "NEON 40" FE-SEM (Carl Zeiss SMT AG, Oberkochen, Germany) at an acceleration voltage of $20 \mathrm{kV}$.

\subsection{X-ray photoelectron spectroscopy}

Surface chemical characterization was performed by means of X-ray photoelectron spectroscopy (XPS) implemented in an ESCA+ facility (Oxford Instruments, Taunusstein, Germany) at a base pressure $<3.0 \times 10^{-10}$ mbar using monochromatic $\mathrm{Al} \mathrm{K \alpha}$ radiation $(1486.7 \mathrm{eV})$. No neutralisation was used. The calibration was performed using the $\mathrm{C}$ 1s signal (at $284.6 \mathrm{eV}$ ) of adventitious carbon as internal reference. The samples were measured using a take-off angle of $30^{\circ}$ with respect to the surface. Surveys were recorded at a pass energy of $100 \mathrm{eV}$ and a step size of $0.2 \mathrm{eV}$ while core level peaks were recorded at a pass energy of $20 \mathrm{eV}$ and a step size of at least $0.1 \mathrm{eV}$.

\subsection{Time-of-flight secondary ion mass spectroscopy}

Time-of-flight secondary ion mass spectroscopy (TOF-SIMS) measurements were performed using a TOF-SIMS 5-100 from IONTOF at the Interdisciplinary Centre for Analytics on the Nanoscale (ICAN) of the University of Duisburg-Essen. As primary ion source, a $30 \mathrm{kV} \mathrm{Bi}^{+}$ion gun operated in spectrometry mode at a nominal lateral resolution of 3-10 $\mu \mathrm{m}$ was used. Secondary metal ions were recorded in positive polarity. Interlaced sputtering was carried out using a $2 \mathrm{kV} \mathrm{Xe}^{+}$ion gun as a secondary ion source. $\mathrm{A} \mathrm{Xe}^{+}$ion gun rather than an $\mathrm{O}_{2}{ }^{+}$ion gun was chosen in order to avoid material oxidation throughout depth profiling.

Two different field size settings were used at otherwise identical instrument parameters. Firstly, an analysis field size of $100 \times 100 \mu \mathrm{m}^{2}$ at a sputter field size of $300 \times 300 \mu \mathrm{m}^{2}$ was used for fast small area depth profiling through the complete ZnMgAl-coatings. The end of the coating was identified by the appearance and stabilization to a constant value of the $\mathrm{Fe}^{+}$ signal (corresponding to the steel substrate). Secondly, an analysis field size of $400 \times 400 \mu \mathrm{m}^{2}$ at a sputter field size of 1000 $\times 1000 \mu^{2}$ was used for large area depth profiling of the surface-near region of the $\mathrm{ZnMgAl}$-films at lower sputtering rates.

\subsection{Water contact angle studies}

Static water contact angle measurements were carried out with an OCA 15 plus (Dataphysics, Germany), using $5 \mu \mathrm{L}$ pure water droplets. The drops were evaluated by the Laurentian method.

\section{$2.990^{\circ}$-peel test under humid conditions}

Peel forces were determined under humid conditions by $90^{\circ}$ peel test measurement for two different adhesives: (a) acrylate adhesive tape (Scotch Magic Tape (3 M, Germany)); (b) 2component epoxy amine adhesive consisting of epoxy resin D.E.R 331 (DOW Chemicals, USA) and amine poly(propylene 
glycol)bis(2-aminopropylether) (Sigma Aldrich, Germany). The application of the adhesive was performed immediately after the plasma treatment.

For the two component epoxy amine adhesive, $3.73 \mathrm{~g}$ of D.E.R. 331 and $2.26 \mathrm{~g}$ poly(propylene glycol)bis(2aminopropylether) were mixed together and then degassed in vacuum $\left(<1 \times 10^{-2} \mathrm{mbar}\right)$ for $2 \mathrm{~h}$. To create well-defined film thickness of $150 \mu \mathrm{m}$, spacers consisting of three layers of commercial adhesive tape were applied on the samples. The adhesive was applied in dry atmosphere $(<6 \%$ r.h.) at room temperature. The coated samples were put on PTFE blocks wrapped with aluminium foil, fixed with clamps and hardened at $120{ }^{\circ} \mathrm{C}$ for $75 \mathrm{~min}$ in an oven. After the hardening, the PTFE block with the aluminium foil and the spacers were removed from the samples.

Magic Tape was applied in dry atmosphere ( $<6 \%$ r.h.) by moving a $2 \mathrm{~kg}$ rubber roller 8 times over the Magic Tape on the sample.

All samples were exposed after the application of the adhesive for $18 \mathrm{~h}$ at $40{ }^{\circ} \mathrm{C}$ to humid air (100\% r.h.). Subsequently the $90^{\circ}$ peel test was performed in a MV-220 Motorized Test Stand (Imada, Japan) at about $85 \%$ r.h. The pull-off force was measured with a gauge of type Model ZP-5 (Imada, Japan). The haul-off speed was set to $1 \mathrm{~mm} \mathrm{~s}^{-1}$.

\section{Results and discussion}

The samples were characterized previously to the plasma treatments with scanning electron microscopy (SEM), energy dispersive X-ray spectroscopy (EDX) and X-ray photoelectron spectroscopy (XPS). The results of these characterizations are shown in the ESI (see Fig. S1 to S3, and Table S1†).

Cross-sectional SEM images show ZnMgAl-coating thickness between 3.5 and $5 \mu \mathrm{m}$ (Fig. 1b). The internal structure of ZnMgAl coatings is not homogeneous but it consists of separated regions of $\mathrm{Zn}$, binary $\mathrm{Zn}_{2} \mathrm{Mg}$ and ternary $\mathrm{ZnMgAl},{ }^{17,18}$ forming dendrites that can reach sizes between 5-10 $\mu \mathrm{m}$ in diameter. ${ }^{17-19}$

The composition as determined by EDX is similar to that of other ZnMgAl alloys in literature, ${ }^{2,18}$ showing a high amount of $\mathrm{Zn}$ of about $80-90$ at\% in the bulk material and a spatialdependent amount of $\mathrm{Mg}$ and $\mathrm{Al}$ between zero and 20 at $\%$ at different $\mathrm{Mg} / \mathrm{Al}$ ratios. XPS measurements show that the uppermost oxide layer is dominated by aluminium oxide. $\mathrm{Mg}$ is also present at the surface but in lower concentrations, while $\mathrm{Zn}$ is almost not existent. The enrichment of $\mathrm{Al}$ and $\mathrm{Mg}$ at the surface is a known aspect of ZnMgAl alloys; however, the enrichment is typically seen to be dominated by $\mathrm{Mg}$, while in our work, Al dominates at the surface-near region. ${ }^{\mathbf{1 8 , 2 0}}$

\subsection{OES studies of the bulk plasma composition}

Optical emission spectroscopy (OES) was performed on the $\mathrm{Ar}$ and $\mathrm{Ar} / \mathrm{H}_{2} \mathrm{O}$ plasmas in order to identify active species in the plasma and to monitor the stability and reproducibility of the plasma discharge (the $\mathrm{Ar} / \mathrm{O}_{2}$ plasma could not be measured due to low emission in the visible range). Characteristic OES spectra of the $\mathrm{Ar}$ and $\mathrm{Ar} / \mathrm{H}_{2} \mathrm{O}$ discharges are shown in Fig. 2.

In general, argon plasmas exhibit emission peaks in the region between 690 and $850 \mathrm{~nm} .{ }^{21}$ These lines were consistently observed in all experiments, with relative intensity ratios characteristic of each gas mixture. Additional emission lines were observed around 300 and $400 \mathrm{~nm}$. These are assigned to hydroxyl $\mathrm{OH}$ radicals $(310 \mathrm{~nm})$ and $\mathrm{N}_{2}$-species $(340,360,380$ $\mathrm{nm}) .{ }^{21}$ We attribute the appearance of these peaks to residual air in the system. Comparing the OES of pure $\mathrm{Ar}$ and $\mathrm{Ar} / \mathrm{H}_{2} \mathrm{O}$ plasmas, the peak at $310 \mathrm{~nm}$ increased by a factor of 4 for the $\mathrm{Ar} /$ $\mathrm{H}_{2} \mathrm{O}$ mixture, while the Ar lines decreased by a similar factor. The decrease of intensity for the Ar lines in the presence of oxygen and water is attributed to quenching of the emission of Ar by water and oxygen molecules.

\subsection{In situ IRRAS studies of surface chemical changes during plasma processing}

Due to its high surface sensitivity, ${ }^{16}$ PM-IRRAS (ex situ) was performed to investigate the IR-active species on the untreated samples. DPM-IRRAS (in situ) was used to identify the plasmainduced changes in the surface, by performing a direct comparison between the samples before and after the plasma exposure. In this case, the reference was a measurement done on the same spot of each sample immediately before the plasma treatment.

The PM-IRRAS spectra of the untreated, cleaned surfaces (Fig. 3a and b) showed signals corresponding to adsorbed water (3200 $\left.\mathrm{cm}^{-1}\right)$, aliphatic carbon groups $\left(2850-2960 \mathrm{~cm}^{-1}\right)$, carboxylates $\left(1620 \mathrm{~cm}^{-1}\right)$, Al-oxide $\left(920 \mathrm{~cm}^{-1}\right)$ and Al-hydroxide $\left(1090 \mathrm{~cm}^{-1}\right)$. The peak assignments are summarised in Table 1.

The presence of carbon groups is associated to the existence of so-called adventitious carbon on the sample surface. Since carboxylates are known to contain aliphatic carbon chains and adsorb on oxide-covered metal surfaces, we infer from the

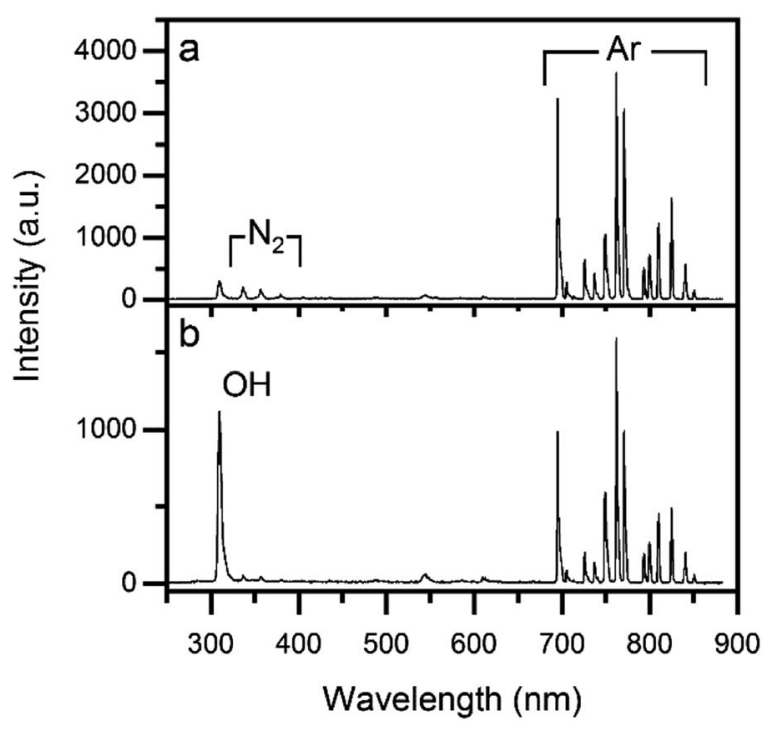

Fig. 2 OES spectra of (a) pure Ar plasma and (b) $\mathrm{Ar} / \mathrm{H}_{2} \mathrm{O}$ plasma. 

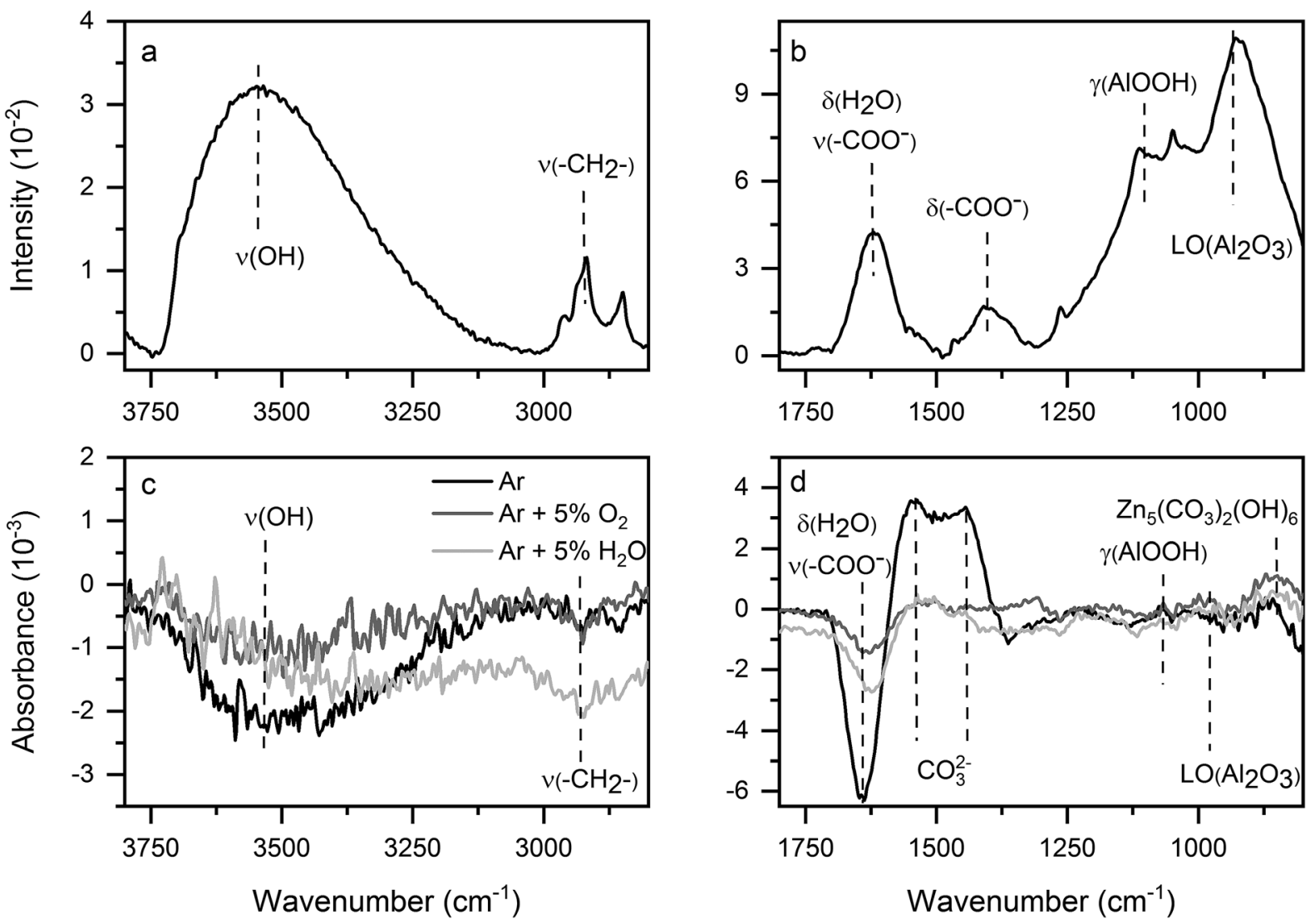

Fig. 3 (a and b) PM-IRRAS of untreated ZnMgAl in two spectra regions. (c and d) In situ DPM-IRRAS of ZnMgAl after 60 s plasma treatment with different gas mixtures with respect to the initial state.

IRRAS measurements that the metal surface is covered by carboxylates containing aliphatic carbon chains. ${ }^{22-25}$ (This assumption is also confirmed by XPS.)

All plasma treatments (Fig. $3 \mathrm{c}$ and d) induced the removal of adsorbed aliphatic species, water and carboxylates, identified by the appearance of negative bands at the corresponding band positions. Further, all plasma treatments build up carbonates. Two different (positive) bands were associated to carbonates: a peak at $860 \mathrm{~cm}^{-1}$, corresponding to zinc carbonate in form of hydrozincite, ${ }^{2,26}$ and a broad band centred around $1500 \mathrm{~cm}^{-1}$, due to un-specified carbonates. Carbonate bands appear typically in a broad spectral region between $1540-1150 \mathrm{~cm}^{-1}$ and the precise band position depends both on the type of substrate ${ }^{2,26-28}$ and on the binding mechanism. ${ }^{27-29}$ The two observed carbonate signals appear after all plasma treatments, independently of the gas mixture used. Additionally, the increase of the carbonate peaks was correlated to the decrease in the carboxylate band, suggesting that the plasma treatments

Table 1 Summary of the peaks observed by means of PM-IRRAS and DPM-IRRAS before and after the plasma treatments

Peak position $\left(\mathrm{cm}^{-1}\right)$

\begin{tabular}{|c|c|c|c|c|}
\hline Solvent cleaned & Ar plasma & $\mathrm{Ar} / \mathrm{O}_{2}$ plasma & $\mathrm{Ar} / \mathrm{H}_{2} \mathrm{O}$ plasma & Peak assignment \\
\hline & 860 & 855 & 860 & $\mathrm{Zn}_{5}\left(\mathrm{CO}_{3}\right)_{2}(\mathrm{OH})_{6}{ }^{2,26}$ \\
\hline 920 & - & 940 & 940 & $\mathrm{LO}\left(\mathrm{Al}_{2} \mathrm{O}_{3}\right)^{30}$ \\
\hline 1020 & 1020 & 1020 & 1020 & $\delta(\mathrm{OCH})^{29}$ \\
\hline \multirow[t]{2}{*}{1090} & 1070 & 1070 & 1070 & $\gamma(\mathrm{AlOOH})^{30,31}$ \\
\hline & $1150-1320$ & $1150-1320$ & $1150-1320$ & Absorbed $\mathrm{CO}_{3}{ }^{2-}$ \\
\hline 1440 & 1440 & 1450 & 1450 & $\delta\left(\mathrm{CO}_{2}{ }^{-}\right)$from both carbonates and carboxylates ${ }^{27,28,31}$ \\
\hline 1465 & & & & $\delta\left(\mathrm{CH}_{2}\right)^{31}$ \\
\hline 1540 & 1535 & 1520 & 1510 & Absorbed $\mathrm{CO}_{3}{ }^{2-}$ \\
\hline 1620 & 1630 & 1630 & 1625 & $\nu\left(\mathrm{CO}_{2}^{-}\right)$from carboxylates, ${ }^{28,32} \delta\left(\mathrm{H}_{2} \mathrm{O}\right)^{30}$ \\
\hline $2850-2960$ & $2850-2960$ & $2850-2960$ & $2850-2960$ & $\nu_{\mathrm{s}}\left(\mathrm{CH}_{2}\right), \nu_{\mathrm{s}}\left(\mathrm{CH}_{3}\right), \nu_{\mathrm{a}}\left(\mathrm{CH}_{2}\right), \nu_{\mathrm{a}}\left(\mathrm{CH}_{3}\right)^{28}$ \\
\hline $3500-3200$ & $3500-3200$ & $3500-3200$ & $3500-3200$ & $\nu(\mathrm{OH})^{30}$ \\
\hline
\end{tabular}


converted carboxylates to carbonates. Contact with the plasma therefore seemed to induce a carbonate conversion that affected both the adsorbed "adventitious" carbonates and the metal carbonates incorporated into the oxide layer. Additional modifications to the oxide layer, dependent on the specific gas mixture, can be seen in the changes in the $\mathrm{AlOOH}$ and $\mathrm{Al}_{2} \mathrm{O}_{3}$ bands.

By evaluating at least eight samples per plasma gas mixture, specific changes in surface chemistry after the plasma treatment could be associated unequivocally to the respective plasma gas mixture. The gas mixture mainly determined the conversion of carboxylates and carbonates in terms of the peak intensities as well as the peak positions associated to carbonates in the region between 1540 and $1150 \mathrm{~cm}^{-1}$. The highest carbonate build-up was observed for the case of pure Ar plasma.

To sum up, DPM-IRRAS measurements showed the decrease in aliphatic carbon and absorbed water and the conversion of carboxylates to carbonates as a results of the of the plasma treatment. The conversion degree was seen to depend on the plasma gas mixture.

\subsection{Ex situ XPS analysis of surface chemical changes after plasma processing}

XPS was used for additional ex situ chemical characterization of the sample surface before and after the plasma treatments. The average stoichiometry (several samples were characterized for each treatment) is presented in Table 2. The ratio between the metals was calculated by dividing the metal concentration by the Zn-concentration.

All investigated samples showed only the presence of $\mathrm{Al}, \mathrm{Mg}$ and Zn plus oxygen and carbon (Fig. S3†). From the stoichiometric data shown in Table 2, it can be seen that the metal component of the untreated surface is dominated by Al. The high $\mathrm{C}$ concentration is due to adventitious carbon, as already reported for similar samples..$^{17,18}$

As already observed in the IR analysis, XPS characterization showed the removal of surface carbon after all plasma treatments. The C1s core level peaks were fitted into four components (Fig. 4). The component at $284.6 \mathrm{eV}$ is associated to aliphatic carbon species, the component at $285.1 \mathrm{eV}$ to ethers, the component at $288.2 \mathrm{eV}$ to carboxylates and the component at $289.2 \mathrm{eV}$ to carbonates. ${ }^{28,33}$ As can be seen in Fig. 4, the plasma treatments led to a distinct increase in carbonate species, while all other components decreased in intensity.

In order to compare the absolute amounts of carboxylate and carbonates, the peak percentage corresponding to each peak component was normalized to the total at\% of carbon as
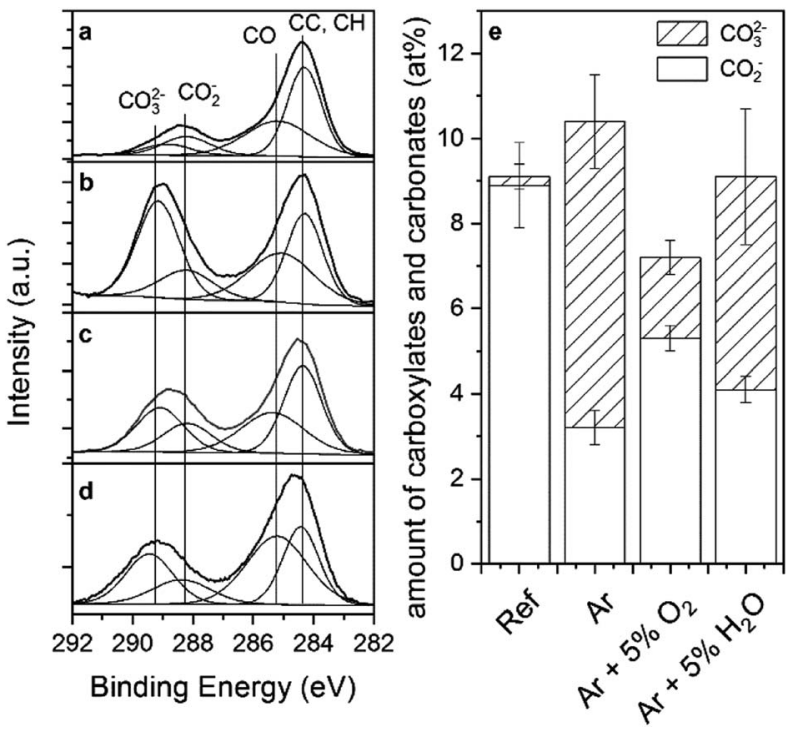

Fig. 4 Element spectra of $\mathrm{C}$ 1s before (a) and after the plasma treatment with $\mathrm{Ar}$ (b), $\mathrm{Ar} / \mathrm{O}_{2}$ (c) and $\mathrm{Ar} / \mathrm{H}_{2} \mathrm{O}$ (d). Quantification of carboxylates and carbonates determined by XPS before and after the plasma treatments (e).

determined by XPS (Fig. 4e). Interestingly, the sum of carboxylates and carbonates remained nearly constant during the plasma process and only the ratio of carbonates to carboxylates changed. Thus, the conversion from carboxylates to carbonates implied by the IR analysis was confirmed by XPS. As already seen in the IR spectra, XPS also confirmed that plasma treatments with pure Ar resulted in the highest carbonate formation, and $\mathrm{Ar} / \mathrm{O}_{2}$ the smallest.

Interestingly, the different plasma treatments influenced as well the metal ratios at the near-surface region. In all cases, the Al concentration decreased. Pure Ar plasma led to a strong increase in $\mathrm{Mg}$, while $\mathrm{Ar} / \mathrm{H}_{2} \mathrm{O}$ plasma mainly caused a surface enrichment of $\mathrm{Zn}$. Changes in surface composition after exposure to low pressure plasmas have already been reported before, ${ }^{9,10}$ and the compositional changes were assigned to a field-induced oxide growth followed by migration. Note that changes in surface composition due to preferential sputtering of the substrate can be excluded due to the small fraction of energetic ions expected to reach the sample surface owing to the high collision rate in the gas phase in an atmospheric-pressure plasma. ${ }^{34,35}$

In the untreated samples, the core level peaks of $\mathrm{Mg} 1 \mathrm{~s}$ showed a fully oxidized $\mathrm{Mg}$ component while in the case of

Table 2 Quantitative XPS analysis of ZnMgAl before and after the respective plasma treatments

\begin{tabular}{|c|c|c|c|c|c|c|}
\hline Substrate treatment & $\mathrm{Zn} 2 \mathrm{p}_{3 / 2}[\mathrm{at} \%]$ & $\mathrm{Mg}$ 1s [at\%] & $\mathrm{Al} 2 \mathrm{p}$ [at\%] & O 1s [at\%] & C 1s [at\%] & $\mathrm{Zn}: \mathrm{Mg}: \mathrm{Al}$ \\
\hline Reference (solvent cleaned) & $0.9 \pm 0.3$ & $2.2 \pm 0.4$ & $12.3 \pm 1.8$ & $41.3 \pm 2.8$ & $43.3 \pm 2.7$ & $1: 2.7: 16.3$ \\
\hline $\mathrm{Ar}$ & $1.6 \pm 0.4$ & $5.3 \pm 0.2$ & $15.7 \pm 0.7$ & $58.1 \pm 1.0$ & $19.3 \pm 3.5$ & $1: 3.5: 10.6$ \\
\hline $\mathrm{Ar}+5 \% \mathrm{H}_{2} \mathrm{O}$ & $3.5 \pm 0.3$ & $4.6 \pm 0.6$ & $10.6 \pm 0.7$ & $54.7 \pm 1.1$ & $26.8 \pm 1.3$ & $1: 1.3: 3$ \\
\hline
\end{tabular}


the $\mathrm{Al} 2 \mathrm{p}$ and $\mathrm{Zn} 2 \mathrm{p}$ peaks, weak components associated to metallic $\mathrm{Zn}$ and $\mathrm{Al}$ were seen (Fig. S4†). The oxidation and hydroxylation of aluminium due to the plasma treatment could be seen by DPM-IRRAS. This effect is consistent with the XPS characterization, since the metallic component of the $\mathrm{Al} 2 \mathrm{p}$ peak was seen to decrease (the same effect was observed in the $\mathrm{Zn} 2 \mathrm{p}$ core level peak). However, it was not possible to distinguish between metal oxides, hydroxides and carbonates, neither in the core level peaks nor by evaluation of the Auger parameters. ${ }^{36,37}$

In order to further investigate the oxidation of the metals, the top oxide layer thickness was estimated following Strohmeier, assuming separated oxide phases (constants used for the calculation shown in Table $\mathrm{S} 2 \dagger) .{ }^{38}$ Please note that this is just a rough estimation, since the actual oxide layer at the surface is inhomogeneous, both in composition and in structure. The results are presented in Fig. 5.

Ar plasma treatment exhibited a certain increase in the thickness of the oxide layer for both $\mathrm{Zn}$ and $\mathrm{Al}$; the addition of oxygen containing species led to an enhancement of this effect. Thus, as expected, the generation of oxidizing species seems to be the determining factor for the increase in the oxide layer thickness, although why an Ar plasma treatment would induce the oxidation of the surface is not fully understood. In pure $\mathrm{Ar}$ plasma, the presence of $\mathrm{OH}$ species was determined by OES and they might be causing the surface oxidation in this case. Adding $\mathrm{O}_{2}$ to $\mathrm{Ar}$ increased the oxide layer thickness slightly, while the addition of $\mathrm{H}_{2} \mathrm{O}$ led to a significant enhancement of the oxidizing properties. Thus, water seems to have a higher oxidizing effect than oxygen in this case.

To summarize, XPS confirmed the removal of surface contamination (aliphatic carbon chains) and the conversion of carboxylates to carbonates. Additionally, XPS showed the migration of $\mathrm{Zn}$ and $\mathrm{Mg}$ towards the surface and an increase in the oxide layer thickness.

\subsection{TOF-SIMS imaging and depth profiling}

After XPS showed that the metal ratios changed at the nearsurface sample region, TOF-SIMS was used to investigate the

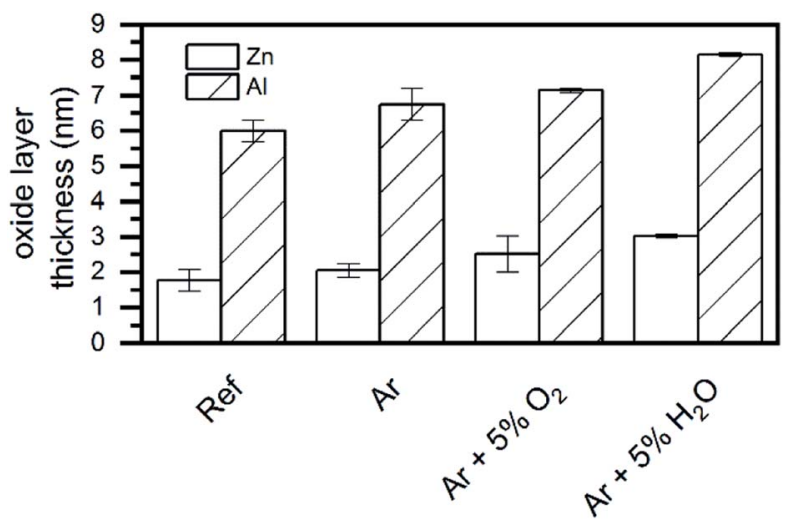

Fig. 5 Calculated oxide layer thickness on ZnMgAl based on the evaluated $\mathrm{Zn} 2 \mathrm{p}$ and $\mathrm{Al} 2 \mathrm{p}$ before and after plasma treatments. lateral and in-depth redistribution of elements as a result of the plasma treatments.

In ToF-SIMS, secondary ion intensities generally depend on both the specific secondary ion of interest and the matrix. ${ }^{39}$ If matrix effects can be neglected, intensities of a given secondary ion (such as $\mathrm{Zn}^{+}, \mathrm{Mg}^{+}$or $\mathrm{Al}^{+}$in this case) could be directly compared between different materials. However, the $\mathrm{ZnMgAl}$ coating shows an inhomogeneous structure at the micro- and nanoscale, so that matrix effects cannot be excluded in this case. Thus, the intensities can only be compared between the ZnMgAl samples. Moreover, oxygen, e.g. as present in surface oxide layers, is known to increase the signal intensity of metal secondary ions by several orders of magnitude. ${ }^{39}$ These general complications have to be kept in mind when discussing and interpreting the TOF-SIMS data.

The depth profiles of the major secondary metal ions, $\mathrm{Zn}^{+}$, $\mathrm{Mg}^{+}$and $\mathrm{Al}^{+}$, are presented in Fig. 6. The curves of $\mathrm{Mg}^{+}$and $\mathrm{Al}^{+}$ secondary ions showed similar behaviour with depth: an initial increase of the signal, followed by a maximum and progressive decrease. This trend is similar to the signals of the corresponding metal oxide cluster signals, i.e. $\mathrm{MgO}^{+}$and $\mathrm{AlO}^{+}$(see ESI, Fig. S6†). Hence, in a first approximation, it could be said that the profiles show the distribution of the superficial oxide layer. After all plasma treatments, a shift of the intensity maximum towards the bulk was observed, indicating the growth of the oxide layer.

Interestingly, the $\mathrm{Zn}^{+}$secondary ions showed a somewhat different depth profile than $\mathrm{Mg}^{+}$and $\mathrm{Al}^{+}$. In the untreated

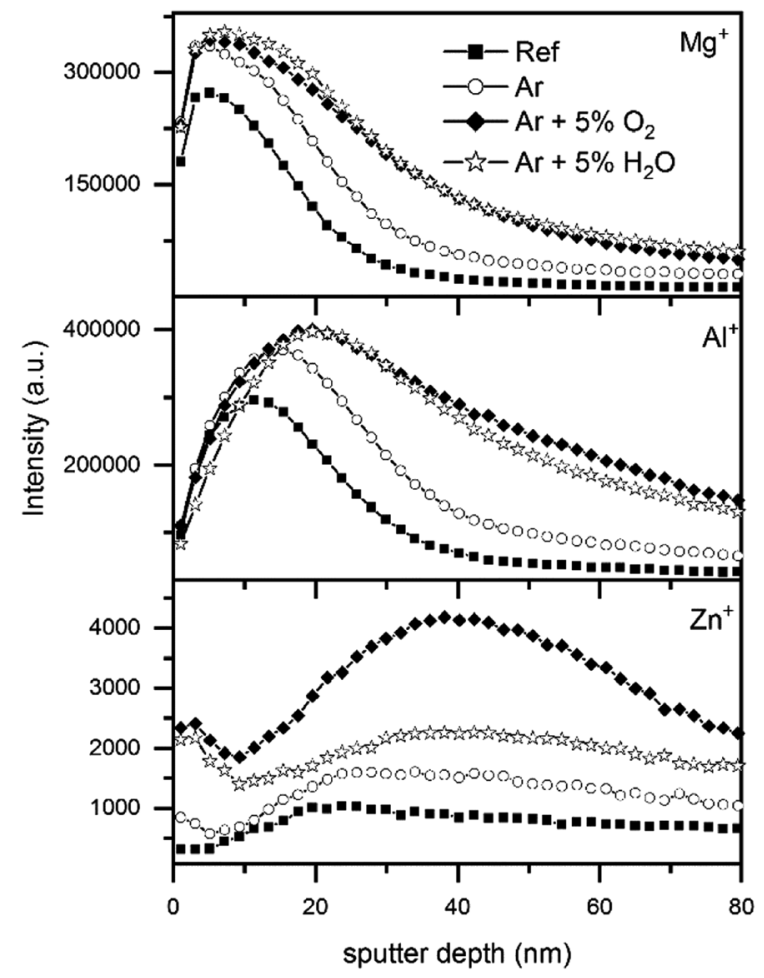

Fig. 6 TOF-SIMS depth profiles of the secondary metal ions $\mathrm{Mg}^{+}, \mathrm{Al}^{+}$ and $\mathrm{Zn}^{+}$for untreated samples and samples with plasma treatments using different gas mixtures. 
sample, the $\mathrm{Zn}^{+}$signal at the surface was low and increased with increasing depth, reaching a steady state for depths below $20 \mathrm{~nm}$. This curve is consistent with the reported accumulation of $\mathrm{Al}$ and $\mathrm{Mg}$ on the surface of $\mathrm{ZnMgAl}$. After all plasma treatments, Zn was enriched at the outermost surface as already seen by XPS. Note however, that the $\mathrm{Zn}^{+}$signal of the plasma-treated ZnMgAl samples did not reach a steady state with increasing depth as in the case of the untreated sample: after an initial decrease with depth (around $5 \mathrm{~nm}$ ), the signal increased again, reaching a maximum between 20 and $60 \mathrm{~nm}$ depth before decreasing once more.

The TOF-SIMS analysis of the first $10 \mathrm{~nm}$ (Fig. S7†) showed that the top oxide layer, both before and after the plasma treatments was homogeneous over surface areas of up to 400 $\mu \mathrm{m}$, independently of the structures underneath and consisted of $\mathrm{Al}$ und $\mathrm{Mg}$.

Therefore, TOF-SIMS could confirm the growth in the oxide layer thickness seen by XPS and additionally revealed plasma induced changes in a depth of several $\mathrm{nm}$. The homogeneity of the top oxide layer over large areas is not affected by the plasma.

\subsection{Kelvin probe studies of average surface potentials after plasma processing}

Kelvin probe measurements were performed in situ to follow the plasma-induced changes in the surface potential, which include changes to the adsorbate layer, metal state and semiconducting properties. By measuring $\mathrm{KP}$ it is possible to evaluate the Galvani potential, which describes the potential necessary to remove from the surface a Fermi-level electron. The Galvani potential difference $\left(\Delta \phi_{\mathrm{Ref}}^{\mathrm{Me}}\right)$ measured by the KP between the underlying metal and the Kelvin probe is determined by the sum of all potential differences of all interfaces according to formula (4): ${ }^{40}$

$$
\Delta \phi_{\mathrm{Ref}}^{\mathrm{Me}}=\Delta \phi_{\mathrm{ox}}^{\mathrm{Me}}+\Delta \phi_{\mathrm{ox}}+\chi_{\mathrm{ox}}+\Delta \Psi_{\mathrm{Ref}}^{\mathrm{ox}}-\chi_{\mathrm{Ref}}
$$

where $\Delta \phi_{\mathrm{ox}}^{\mathrm{Me}}$ is the potential difference between the oxide and the metal. $\Delta \phi_{\text {ox }}$ describes the potential drop across the oxide layer and is determined by such factors as chemical composition, oxide thickness and conductivity of the oxide layer. ${ }^{22,40,41}$ $\chi_{\mathrm{ox}}$ is the surface potential of the oxide and is determined by the absorbed layer on the oxide. Thereby, dipoles formed on the oxide surface play a great role as well as the intrinsic dipole moment of the adsorbed layer. ${ }^{22,23} \Delta \Psi_{\text {Ref }}^{\text {ox }}$ and $\chi_{\text {Ref }}$ are the Volta potential and the surface potential of the probe respectively and are constant values.

KP measurements of at least eight samples were averaged for each plasma gas mixture and the results are shown in Fig. 7.

In all cases, a positive shift of the potential was seen after the plasma treatments. According to the IR and XPS characterizations, the chemical changes induced by the plasma treatments can be summarized as follows: (i) removal of adventitious carbon, (ii) conversion of carboxylates to carbonates, (iii) migration of $\mathrm{Mg}$ and $\mathrm{Zn}$ towards the surface and (iv) increased thickness of the upper oxide layer. The influence of the four effects in the surface potential are discussed in the following.

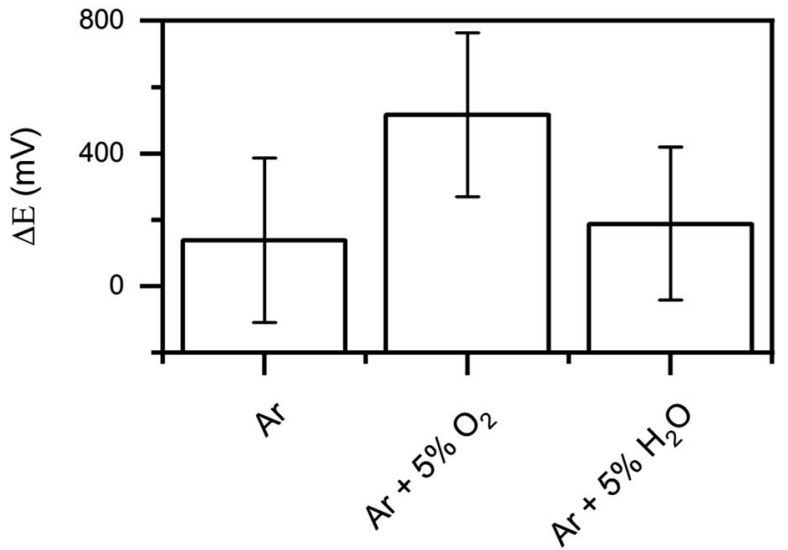

Fig. 7 Differences in the surface potential before and after the respective plasma treatment measured in situ with the KP on ZnMgAl. The error bars are the statistic of at least 8 samples per plasma gas mixture.

(i) When adsorbed adventitious carbon and water are removed from the surface, the distribution of surface dipoles changes, with the corresponding effect on the surface potential $\left(\chi_{\text {ox }}\right)$. Taheri et al. investigated absorbed layer on Zn-surfaces and showed that adsorption of contamination on the surface shifted the potential to more positive values. ${ }^{22}$ Thus, the removal of surface contaminations should result in a negative shift in the surface potential.

(ii) Absorbed carboxylates form a strong dipole at the surface and therefore strongly influence the surface potential $\left(\chi_{\mathrm{ox}}\right)^{22,23}$ At the same time, the intrinsic dipole moment of carboxylates attached with an aliphatic tail orientated away from the surface is zero and does not contribute to the overall potential drop in the adsorbate layer. ${ }^{22,23}$ Changes in the structure of the carboxylates lead to a change in the intrinsic dipole moment different than zero and therefore change the overall potential. Consequently, the conversion from carboxylates to carbonates influences the dipole moment at the surface as well as the intrinsic dipole moment of the adsorbate layer.

(iii) The migration of the metals can influence the potential difference between the metal and the oxide $\left(\Delta \phi_{\mathrm{ox}}^{\mathrm{Me}}\right)$ when new boundaries are formed. Due to the complex structure of the oxide/metal interface, the influence of the migration cannot be assessed.

(iv) A growth in the oxide layer thickness leads to a positive shift of the potential drop over the oxide layer $\left(\Delta \phi_{\text {ox }}\right)^{40,41}$

The overall positive shift of the potential after the plasma treatments is therefore a combination of the positive shift induced by the oxide layer growth and the changes in the dipole distribution of the adsorbate layer.

\subsection{SKPFM imaging of surface potentials}

Ex situ characterization of the samples by scanning Kelvin probe force microscopy (SKPFM) was performed before and after the plasma treatments to evaluate the surface roughness and the $2 \mathrm{D}$ distribution of the surface potential. 
The SKPFM mappings (Fig. 8a-d) revealed a structure similar to FE-SEM and TOF-SIMS measurements, both in topography and surface potential. Fig. 8a and b show the situation corresponding to the untreated sample. Previous characterization of such alloys, such as the one done by Lostak et al. showed that the surface potential depends on the local bulk composition for $\mathrm{ZnMgAl}$ alloys. ${ }^{17}$ Indeed, given the clear compositional inhomogeneity of the sample, one would expect potential variations corresponding to the individual standard potentials of the separated phases. The mapping shown in Fig. 8b, however, shows relatively small standard potential variations. This is most probably due to the muffling effect of the thin top oxide layer, whose homogeneity over large areas of the sample was determined by the ToF-SIMS measurements presented before. After plasma treatment, the variations in surface potential along the surface area are even smaller. To evaluate the changes, the $R_{\mathrm{q}}$ value for the height maps (roughness) and for the potential maps (potential range) were calculated (Fig. 8e and f). All samples exhibited high roughness $\left(300 \mathrm{~nm}\right.$ on a $70 \times 70 \mu \mathrm{m}^{2}$ scale), which was not affected by the plasma treatments. However, as already mentioned, the surface potential showed a distinct homogenisation after the plasma treatment with $\mathrm{Ar} / \mathrm{O}_{2}$ and $\mathrm{Ar} / \mathrm{H}_{2} \mathrm{O}$. The potential homogenisation correlates with the increase of the oxide layer thicknesses determined by XPS and TOF-SIMS. With increasing oxide layer thickness, the influence of the bulk material (in-homogeneously distributed) on the surface is reduced, thus leading to a more homogenous surface potential. Additionally, the conversion of carboxylates to carbonates on the surface, with the corresponding redistribution of surface dipoles, might also affect the surface potential.

\subsection{Water contact angle studies}

Water contact angles were measured to investigate the change in the wettability of the surface after the plasma treatments. The results are shown in Fig. 9.

The untreated surface showed a high contact angle of $70^{\circ}$. This is explained by the presence of the native carboxylate adsorption layer. This leads to an un-polar surface due to the presence of aliphatic carbon chains. As already discussed, one of the main results of the plasma treatments is the removal of these aliphatic chains, which should result in an increase of surface wettability. As expected, the contact angle was reduced to around $20^{\circ}$ in all cases after the plasma treatment. The $\mathrm{Ar} / \mathrm{O}_{2}$ plasma, which showed the lowest removal rate of aliphatic carbon, was thus resulting in the highest contact angle.

\subsection{Peel test studies for the analysis of surface adhesive properties}

Peel test was used to investigate the influence of the plasma treatments on the adhesion strength for an acrylate adhesive tape and an epoxy amine adhesive. The results are presented in Fig. 10.

The peel forces measured for the epoxide amine adhesive on the untreated surface were in the same range as reported in the literature. ${ }^{42,43}$ The acrylate showed a higher peel force than the epoxide amine adhesive. The adsorption of polyacrylic acid molecules to metal oxides such as $\mathrm{Al}_{2} \mathrm{O}_{3}$ and $\mathrm{ZnO}$ has been deeply studied by several authors. ${ }^{44,45}$ We assume that the reason for the increased adhesion forces in the case of acrylate based adhesive is that carboxylic groups form strong acid-base interactions with the surface metal ions due bidentate bindings.
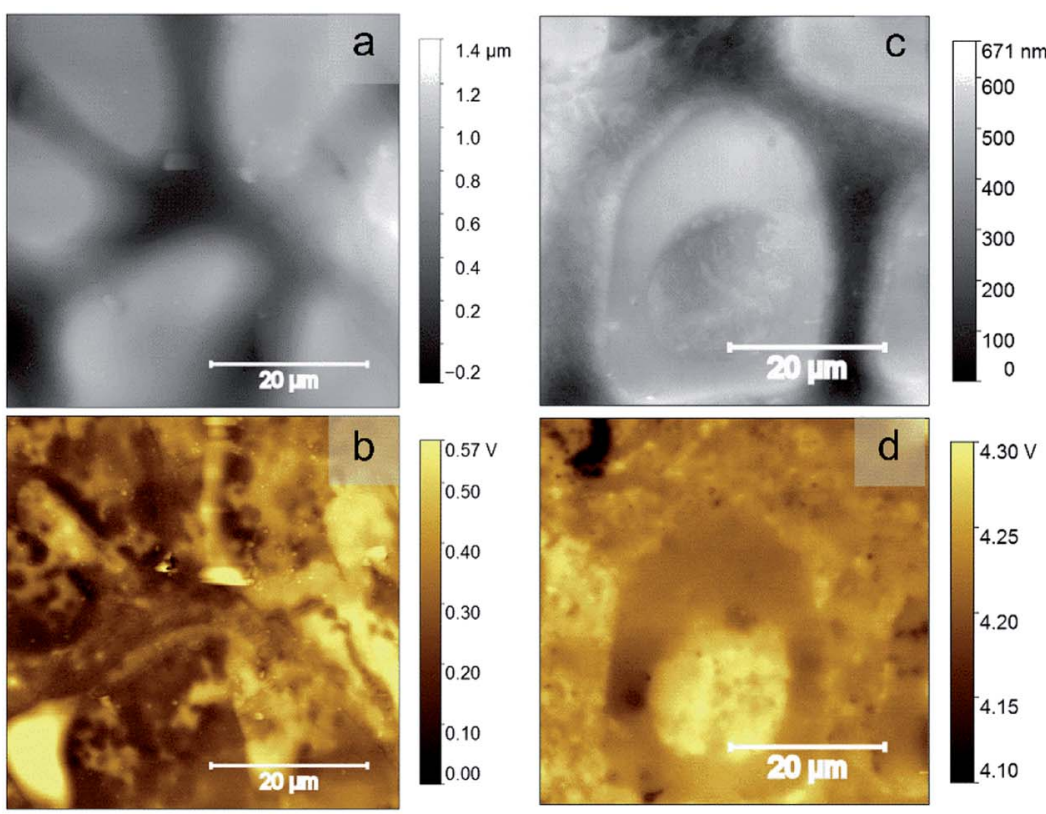

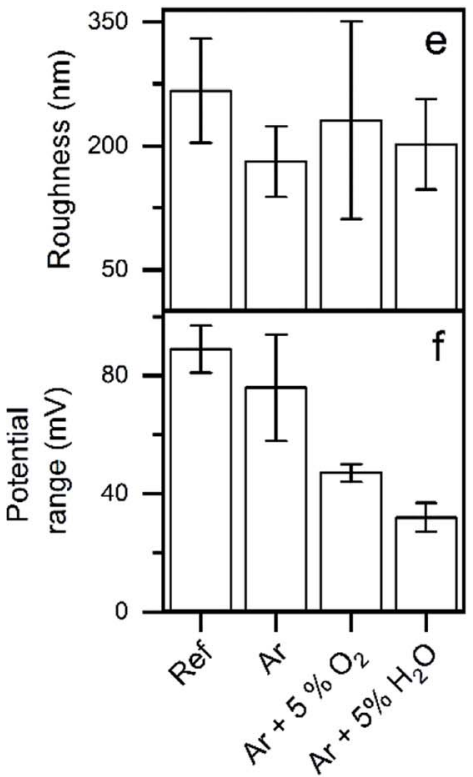

Fig. 8 SKPFM mappings of an untreated ZnMgAl alloy ((a) topography and (b) surface potential) compared to a sample plasma treated with Ar/ $\mathrm{H}_{2} \mathrm{O}$ ((c) topography and (d) surface potential). (e) Evaluation of the roughness and (f) the surface potential range before and after the respective plasma treatment. 


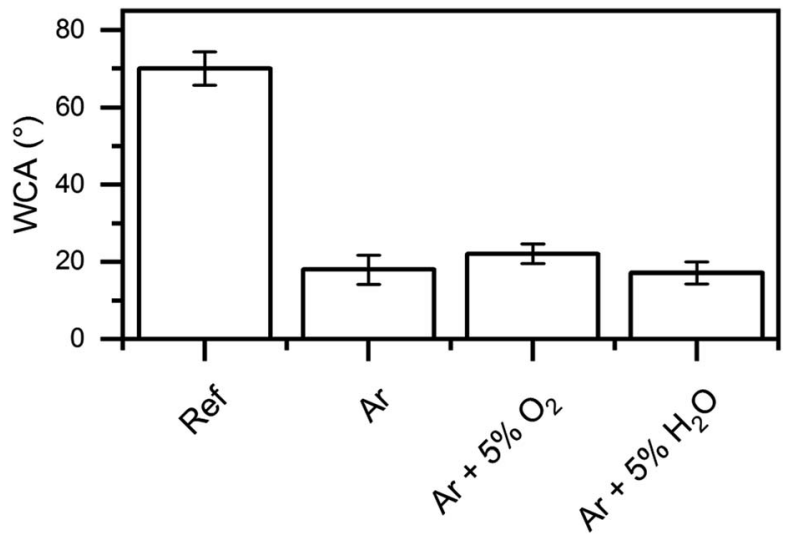

Fig. 9 Water contact angle measurements before and after the plasma treatments.

By comparison, the amine and alcohol functions of the epoxy amine adhesive form interfacial monodentate bonds.

The peel force was increased by all plasma treatments for both adhesives. Plasma treatments with $\mathrm{Ar}$ and $\mathrm{Ar} / \mathrm{O}_{2}$ showed only small increases in the peel force, while plasma treatments with $\mathrm{Ar} / \mathrm{H}_{2} \mathrm{O}$ led to a significant increase for both adhesives. The increase was particularly distinctive in the case of the epoxy amine adhesive, where the peel force was improved by a factor of 3. This increase in the peel force is in the range of improvements introduced by commonly used adhesion promotion layers such as $\gamma$-APS. ${ }^{43}$

As already discussed, the surface of untreated $\mathrm{ZnMgAl}$ is made of an oxyhydroxide surface, covered by a layer of adsorbed carboxylates and aliphatic carbon groups. When an adhesive is applied to this surface, the acid-base interaction of the polar groups of the adhesive with the metal surface is hindered by the presence of the aliphatic carbon groups, which are not polar in nature. The plasma treatments etch the aliphatic carbon groups and convert carboxylates to carbonates. The conversion to carbonates (polar) combined with the loss of the aliphatic carbon groups leads to a better interaction of the adhesive with the surface.

Nevertheless, plasma treatments with small carbonate conversion, such as the $\mathrm{Ar} / \mathrm{O}_{2}$ plasma, show a significant increase in adhesion between adhesive and surface as well. That



Fig. 10 Peel test results before and after the plasma treatment for acrylate coated tape and epoxy amine adhesive. suggests that additional mechanisms might need to be taken into account. While pure Ar plasma mainly created carbonates combined with the etching of aliphatic carbon groups, $\mathrm{Ar} / \mathrm{O}_{2}$ plasma primarily induced an increase in the oxide layer thickness followed by a homogenisation of the surface potential. Both processes led to a similar increase in the peel force independent of the adhesive. It is important to note that plasma treatments with $\mathrm{Ar} / \mathrm{H}_{2} \mathrm{O}$, which induce all the discussed effects in a high degree, showed the highest performance with both adhesives, thus showing the synergistically nature of the plasma-induced changes on the adhesion. How this combination of factors in detail affects the overall adhesive properties of the surface is not clear at present.

\section{Conclusions}

A combination of the surface characterization techniques DPMIRRAS, XPS, KP, TOF-SIMS and SKPFM allowed the identification of five different plasma-induced surface effects in the DBD plasma treatment of $\mathrm{ZnMgAl}$ alloys. The effects are: surface conversion of carboxylates to carbonates, etching of aliphatic carbon groups, migration of metals, increased top oxide layer, and homogenization of the surface potential. These changes appear in greater or lesser degree depending on the gas mixture. Although an improvement of adhesion properties and wettability was observed after all plasma treatments, there was not a clear correlation between a specific surface effect and the improved adhesion behaviour. Ar plasma, which mostly produced the etching of aliphatic chains and conversion of carboxylates to carbonates of the surface, showed a similar improvement in adhesion as the $\mathrm{Ar} / \mathrm{O}_{2}$ plasma, where the main effect was the increased oxide layer and homogenization of surface potential. Interestingly, treatment with the $\mathrm{Ar} / \mathrm{H}_{2} \mathrm{O}$ plasma, which induced all discussed effects in high degree, resulted in the highest adhesive improvement, suggesting that all effects synergistically contribute to the final improvement. The improved adhesion after removal of aliphatic carbon chains and the conversion of carboxylates to carbonates of the surface can be partly explained by the formation of polar groups at the surface that can interact with the polar groups of the adhesive. However, it is not fully understood at present how the combination of all observed factors collectively affect the adhesion.

\section{Conflicts of interest}

There are no conflicts to declare.

\section{Acknowledgements}

The authors of this work kindly acknowledge the German Research Foundation (GR 1709/19-1) for financial support. Support by the Interdisciplinary Center for Analysis on the Nanoscale (ICAN) of the University of Duisburg-Essen, a DFG core facility (reference RI_00313), is gratefully acknowledged (supply of TOF-SIMS data in service operation). 


\section{Notes and references}

1 X. Zhao, J. Su, G. Li, J. He, S. Chen, G. Wang and A. Liu, The electrochemical behavior of $\mathrm{Mg}-9 \mathrm{Al}-0.5 \mathrm{Zn}, \mathrm{Mg}-9 \mathrm{Al}-0.7 \mathrm{Zn}$, and $\mathrm{Mg}-9 \mathrm{Al}-1.0 \mathrm{Zn}$ in a $\mathrm{NaCl}$ solution, Mater. Corros., DOI: 10.1002/maco.201910869.

2 E. Diler, B. Rouvellou, S. Rioual, B. Lescop, G. Nguyen Vien and D. Thierry, Characterization of corrosion products of $\mathrm{Zn}$ and $\mathrm{Zn}-\mathrm{Mg}-\mathrm{Al}$ coated steel in a marine atmosphere, Corros. Sci., 2014, 87, 111-117, DOI: 10.1016/ j.corsci.2014.06.017.

$3 \mathrm{H}$. Medhashree and A. N. Shetty, Electrochemical investigation on the effects of sulfate ion concentration, temperature and medium $\mathrm{pH}$ on the corrosion behavior of $\mathrm{Mg}-\mathrm{Al}-\mathrm{Zn}-\mathrm{Mn}$ alloy in aqueous ethylene glycol, $J$. Magnesium Alloys, 2017, 5, 64-73, DOI: 10.1016/ j.jma.2016.12.003.

4 M. Salgueiro Azevedo, C. Allély, K. Ogle and P. Volovitch, Corrosion mechanisms of $\mathrm{Zn}(\mathrm{Mg}, \mathrm{Al})$ coated steel: 2 the effect of $\mathrm{Mg}$ and $\mathrm{Al}$ alloying on the formation and properties of corrosion products in different electrolytes, Corros. Sci., 2015, 90, 482-490, DOI: 10.1016/ j.corsci.2014.07.042.

5 A. van Deynse, N. D. Geyter, C. Leys and R. Morent, Influence of Water Vapor Addition on the Surface Modification of Polyethylene in an Argon Dielectric Barrier Discharge, Plasma Processes Polym., 2014, 11, 117-125, DOI: 10.1002/ ppap.201300088.

$6 \mathrm{~S}$. B. Lee and Y. -K. Kim, Adhesion Improvement of Polyimide/Metal Interface by $\mathrm{He} / \mathrm{O}_{2} / \mathrm{NF}_{3}$ Atmospheric Pressure Plasma, Plasma Processes Polym., 2009, 6, S525S529, DOI: 10.1002/ppap.200931111.

7 D. Lee, S. H. Hong, K.-H. Paek and W.-T. Ju, Adsorbability enhancement of activated carbon by dielectric barrier discharge plasma treatment, Surf. Coat. Technol., 2005, 200, 2277-2282, DOI: 10.1016/j.surfcoat.2004.11.027.

8 B. K. Kim, K. S. Kim, C. E. Park and C. M. Ryu, Improvement of wettability and reduction of aging effect by plasma treatment of low-density polyethylene with argon and oxygen mixtures, J. Adhes. Sci. Technol., 2002, 16, 509-521, DOI: $10.1163 / 156856102760070349$.

9 M. Giza and G. Grundmeier, Combination of FTIR Reflection Absorption Spectroscopy and Work Function Measurements for In Situ Studies of Plasma Modified Passive Films on $\mathrm{MgZn}_{2}$, Plasma Processes Polym., 2011, 8, 607-616, DOI: 10.1002/ppap.201000198.

10 K. Pohl, J. Otte, P. Thissen, M. Giza, M. Maxisch, B. Schuhmacher and G. Grundmeier, Adsorption and stability of self-assembled organophosphonic acid monolayers on plasma modified $\mathrm{Zn}-\mathrm{Mg}-\mathrm{Al}$ alloy surfaces, Surf. Coat. Technol., 2013, 218, 99-107, DOI: 10.1016/ j.surfcoat.2012.12.035.

11 Y. Hu, Y. Yang, L. Yan, X. Zhu, X. Bai and S. Fan, in Recent developments in applied electrostatics, ed. S. Keping and Y. Gefei, Elsevier, Kidlington, Oxford, UK, 1st edn, 2004, pp. 241-243.
12 Y. Yoshikawa, T. Hara and P. Abraha, Surface Treatment of Tool Steel in Controlled Plasma Nitriding Environment, Tribology Online, 2008, 3, 348-351, DOI: 10.2474/trol.3.348.

13 G. Grundmeier, E. Matheisen and M. Stratmann, Formation and stability of ultrathin organosilane polymers on iron, $J$. Adhes. Sci. Technol., 1996, 10, 573-588, DOI: 10.1163/ $156856196 \times 00599$.

14 A. Tahara and T. Kodama, Potential distribution measurement in galvanic corrosion of $\mathrm{Zn} / \mathrm{Fe}$ couple by means of Kelvin probe, Corros. Sci., 2000, 42, 655-673, DOI: 10.1016/S0010-938X(99)00074-8.

15 I. D. Baikie, E. Venderbosch, J. A. Meyer and P. J. Z. Estrup, Analysis of stray capacitance in the Kelvin method, Rev. Sci. Instrum., 1991, 62, 725-735, DOI: 10.1063/1.1142075.

16 G. Grundmeier, A. von Keudell and T. de los Arcos, Fundamentals and Applications of Reflection FTIR Spectroscopy for the Analysis of Plasma Processes at Materials Interfaces, Plasma Processes Polym., 2015, 12, 926-940, DOI: 10.1002/ppap.201500087.

17 T. Lostak, A. Maljusch, B. Klink, S. Krebs, M. Kimpel, J. Flock, S. Schulz and W. Schuhmann, Zr-based conversion layer on $\mathrm{Zn}-\mathrm{Al}-\mathrm{Mg}$ alloy coated steel sheets: insights into the formation mechanism, Electrochim. Acta, 2014, 137, 65-74, DOI: 10.1016/j.electacta.2014.05.163.

18 N. LeBozec, D. Thierry, M. Rohwerder, D. Persson, G. Luckeneder and L. Luxem, Effect of carbon dioxide on the atmospheric corrosion of $\mathrm{Zn}-\mathrm{Mg}-\mathrm{Al}$ coated steel, Corros. Sci., 2013, 74, 379-386, DOI: 10.1016/ j.corsci.2013.05.011.

19 T. Prosek, J. Hagström, D. Persson, N. Fuertes, F. Lindberg, O. Chocholatý, C. Taxén, J. Šerák and D. Thierry, Effect of the microstructure of $\mathrm{Zn}-\mathrm{Al}$ and $\mathrm{Zn}-\mathrm{Al}-\mathrm{Mg}$ model alloys on corrosion stability, Corros. Sci., 2016, 110, 71-81, DOI: 10.1016/j.corsci.2016.04.022.

20 M. Arndt, J. Duchoslav, H. Itani, G. Hesser, C. K. Riener, G. Angeli, K. Preis, D. Stifter and K. Hingerl, Nanoscale analysis of surface oxides on $\mathrm{ZnMgAl}$ hot-dip-coated steel sheets, Anal. Bioanal. Chem., 2012, 403, 651-661, DOI: 10.1007/s00216-011-5507-0.

21 A. Sarani, A. Y. Nikiforov and C. Leys, Atmospheric pressure plasma jet in $\mathrm{Ar}$ and $\mathrm{Ar} / \mathrm{H} 2 \mathrm{O}$ mixtures: Optical emission spectroscopy and temperature measurements, Phys. Plasmas, 2010, 17, 63504, DOI: 10.1063/1.3439685.

22 P. Taheri, K. Pohl, G. Grundmeier, J. R. Flores, F. Hannour, J. H. W. de Wit, J. M. C. Mol and H. Terryn, Effects of Surface Treatment and Carboxylic Acid and Anhydride Molecular Dipole Moments on the Volta Potential Values of Zinc Surfaces, J. Phys. Chem. C, 2013, 117, 1712-1721, DOI: 10.1021/jp3096049.

23 J. Wielant, R. Posner, G. Grundmeier and H. Terryn, Interface Dipoles Observed after Adsorption of Model Compounds on Iron Oxide Films: Effect of Organic Functionality and Oxide Surface Chemistry, J. Phys. Chem. C, 2008, 112, 12951-12957, DOI: 10.1021/jp802703v.

24 M. Giza, P. Thissen and G. Grundmeier, Adsorption kinetics of organophosphonic acids on plasma-modified oxide- 
covered aluminum surfaces, Langmuir, 2008, 24, 8688-8694, DOI: $10.1021 /$ la8000619.

25 S. Szillies, P. Thissen, D. Tabatabai, F. Feil, W. Fürbeth, N. Fink and G. Grundmeier, Formation and stability of organic acid monolayers on magnesium alloy AZ31: the role of alkyl chain length and head group chemistry, Appl. Surf. Sci., 2013, 283, 339-347, DOI: 10.1016/ j.apsusc.2013.06.113.

26 T. Prosek, A. Nazarov, U. Bexell, D. Thierry and J. Serak, Corrosion mechanism of model zinc-magnesium alloys in atmospheric conditions, Corros. Sci., 2008, 50, 2216-2231, DOI: 10.1016/j.corsci.2008.06.008.

27 C. Weilach, C. Spiel, K. Föttinger and G. Rupprechter, Carbonate formation on $\mathrm{Al}_{2} \mathrm{O}_{3}$ thin film model catalyst supports, Surf. Sci., 2011, 605, 1503-1509, DOI: 10.1016/ j.susc.2011.05.025.

28 C. Fotea, J. Callaway and M. R. Alexander, Characterisation of the surface chemistry of magnesium exposed to the ambient atmosphere, Surf. Interface Anal., 2006, 38, 13631371, DOI: 10.1002/sia.2463.

29 G. N. Vayssilov, M. Mihaylov, P. St. Petkov, K. I. Hadjiivanov and K. M. Neyman, Reassignment of the Vibrational Spectra of Carbonates, Formates, and Related Surface Species on Ceria: A Combined Density Functional and Infrared Spectroscopy Investigation, J. Phys. Chem. C, 2011, 115, 23435-23454, DOI: 10.1021/jp208050a.

30 I. Giner, M. Maxisch, C. Kunze and G. Grundmeier, Combined in situ PM-IRRAS/QCM studies of water adsorption on plasma modified aluminum oxide/ aluminum substrates, Appl. Surf. Sci., 2013, 283, 145-153, DOI: 10.1016/j.apsusc.2013.06.059.

31 A. Strålin and T. Hjertberg, FTIR Study on interfacial interactions between hydrated aluminium and polar groups in ethylene copolymers, Surf. Interface Anal., 1993, 20, 337-340, DOI: 10.1002/sia.740200503.

32 G. Busca and V. Lorenzelli, Infrared spectroscopic identification of species arising from reactive adsorption of carbon oxides on metal oxide surfaces, Mater. Chem., 1982, 7, 89-126, DOI: 10.1016/0390-6035(82)90059-1.

33 M. R. Alexander, G. Beamson, C. J. Blomfield, G. Leggett and T. M. Duc, Interaction of carboxylic acids with the oxyhydroxide surface of aluminium: poly(acrylic acid), acetic acid and propionic acid on pseudoboehmite, $J$. Electron Spectrosc. Relat. Phenom., 2001, 121, 19-32, DOI: 10.1016/S0368-2048(01)00324-3.

34 L. Bárdos and H. Baránková, Cold atmospheric plasma: Sources, processes, and applications, Thin Solid Films, 2010, 518, 6705-6713, DOI: 10.1016/j.tsf.2010.07.044.

35 C. Z. Liu, J. Q. Wu, L. Q. Ren, J. Tong, J. Q. Li, N. Cui, N. M. D. Brown and B. J. Meenan, Comparative study on the effect of RF and DBD plasma treatment on PTFE surface modification, Mater. Chem. Phys., 2004, 85, 340346, DOI: 10.1016/j.matchemphys.2004.01.026.

36 C. D. Wagner and P. Biloen, X-ray excited Auger and photoelectron spectra of partially oxidized magnesium surfaces: The observation of abnormal chemical shifts, Surf. Sci., 1973, 35, 82-95, DOI: 10.1016/0039-6028(73) 90205-7.

37 M. R. Alexander, G. E. Thompson, X. Zhou, G. Beamson and N. Fairley, Quantification of oxide film thickness at the surface of aluminium using XPS, Surf. Interface Anal., 2002, 34, 485-489, DOI: 10.1002/sia.1344.

38 B. R. Strohmeier, An ESCA method for determining the oxide thickness on aluminum alloys, Surf. Interface Anal., 1990, 15, 51-56, DOI: 10.1002/sia.740150109.

39 I. F. Urazgil'din, Secondary ion emission from metal surfaces, Nucl. Instrum. Methods Phys. Res., Sect. B, 1993, 78, 271-277, DOI: 10.1016/0168-583X(93)95810-R.

40 E. Juzeliūnas, A. Sudavičius, K. Jüttner and W. Fürbeth, Study of initial stages of $\mathrm{Al}-\mathrm{Mg}$ alloy corrosion in water, chloride and $\mathrm{Cu}$ (II) environment by a scanning Kelvin probe and XPS, Electrochem. Commun., 2003, 5, 154-158, DOI: 10.1016/S1388-2481(03)00015-8.

41 G. Bäck, A. Nazarov and D. Thierry, Localized Corrosion of Heat-Treated and Welded Stainless Steel Studied Using a Scanning Kelvin Probe, Corrosion, 2005, 61, 951-960, DOI: 10.5006/1.3280895.

42 K. A. Yasakau, I. Giner, C. Vree, O. Ozcan, R. Grothe, A. Oliveira, G. Grundmeier, M. G. S. Ferreira and M. L. Zheludkevich, Influence of stripping and cooling atmospheres on surface properties and corrosion of zinc galvanizing coatings, Appl. Surf. Sci., 2016, 389, 144-156, DOI: 10.1016/j.apsusc.2016.07.093.

43 R. Grothe, M. Wiesing, I. Giner, D. Meinderink and G. Grundmeier, Scanning Kelvin probe blister studies of the delamination of epoxy films on organosilane modified ZnMgAl alloy coated steel, Mater. Corros., 2017, 68, 13141320, DOI: 10.1002/maco.201709462.

44 D. Meinderink, A. G. Orive, S. Ewertowski, I. Giner and G. Grundmeier, Dependance of Poly(acrylic acid) Interfacial Adhesion on the Nanostructure of Electrodeposited ZnO Films, ACS Appl. Nano Mater., 2019, 2, 831-843, DOI: 10.1021/acsanm.8b02091.

45 S. Pletincx, L. Trotochaud, L.-L. Fockaert, J. M. C. Mol, A. R. Head, O. Karslıoğlu, H. Bluhm, H. Terryn and T. Hauffman, In Situ Characterization of the Initial Effect of Water on Molecular Interactions at the Interface of Organic/Inorganic Hybrid Systems, Sci. Rep., 7, 45123, DOI: 10.1038/srep45123. 